\title{
Hyponatraemia in the first week of life in preterm infants
}

\section{Part II Sodium and water balance}

\author{
L REES, J C L SHAW, C G D BROOK, AND M L FORSLING \\ Departments of Paediatrics and Physiology, Middlesex Hospital, and Department of Paediatrics, University \\ College Hospital, London
}

SUMMARY Serial measurements of plasma sodium, sodium balance, water intake, and urine volume were made for a mean period of 5.9 days in 10 preterm infants of mean gestation 30.5 weeks and mean birthweight $1506 \mathrm{~g}$. In five infants weighed regularly, estimates of insensible water loss averaged 2.6 (range 1.4 to $6 \cdot 2$ ) $\mathrm{ml} / \mathrm{kg} / \mathrm{hour}$. High insensible water losses were the cause of hypernatraemia that occurred in two of the 10 infants. Net sodium balance was negative during the study and represented contraction of the extracellular fluid volume associated with weight loss. The negative sodium balance did not seem diminished by increasing sodium intake and there was no evidence that sodium intake need exceed 3 to $4 \mathrm{mmol} / \mathrm{kg} / \mathrm{day}$. Hyponatraemia was not due to changes in sodium balance but to water retention associated with inappropriate increases in urinary arginine vasopressin excretion and urine osmolality in 8 of 10 infants. Frequent, accurate measurements of body weight and of plasma sodium are the two most reliable indicators of changes in water balance.

Both hyponatraemia and hypernatraemia, which may occur in preterm infants during the first few days after birth, result from changes either in total body sodium or total body water, or both. Whether the plasma sodium rises or falls depends, therefore, on the magnitude and direction of change in total body sodium and water and as this information is difficult to obtain in preterm infants, the cause is not always evident and the wrong treatment may be prescribed.

Butterfield et al ${ }^{1}$ showed that preterm infants were in negative sodium balance during the first week of life and concluded that this was an obligatory physiological event associated with weight loss and represented the contraction of the extracellular fluid volume known to occur after birth. ${ }^{2}$ More recently Engelke et al ${ }^{3}$ proposed that the sodium diuresis and associated negative sodium balance they observed in the first week of life were the cause of the hyponatraemia in their infants and suggested that some preterm infants required a very high sodium intake (greater than $7.5 \mathrm{mmol} / \mathrm{kg} /$ day) to prevent hyponatraemia. Lorenz et $a l^{4}$ showed, however, that normal plasma sodium concentrations could be maintained in the first week of life on much lower sodium intakes (in the region of 1 to 3 $\mathrm{mmol} / \mathrm{kg} /$ day) provided careful attention was paid to water balance. Their data suggested that water retention might be a more important cause of hyponatraemia than sodium loss. Causes of hypernatraemia are less controversial; this usually results from high insensible water losses that occur in preterm infants ${ }^{5-7}$ but the contribution of changes in sodium balance have not been studied.

Our purpose was to increase understanding of these problems by making continuous sequential measurements of sodium and water balance and urinary arginine vasopressin excretion in very low birthweight preterm infants during the first week of life to discover the relation between these variables and the plasma sodium concentration.

In this study we have investigated only those infants who had the most severe problems-namely very low birthweight preterm infants with respiratory disease requiring mechanical ventilation. These infants obviously pose enormous difficulties to the investigator and there is least information about them. Results show that water retention, often associated with arginine vasopressin release, rather than negative sodium balance is the main cause of 
hyponatraemia in sick, preterm infants in the first week of life, while excessive insensible water losses are the main cause of hypernatraemia. The factors affecting arginine vasopressin secretion have been reported in detail in Part $\mathrm{I}^{8}$ and here we deal mainly with changes in sodium and water balance and their relation to arginine vasopressin release.

\section{Patients and methods}

Patients. The data presented here are from 10 of the 14 boys studied in Part I. ${ }^{8}$ They were investigated for a period of 5.9 (range 4 to 8 ) days. Four were omitted because of insufficient data on sodium and water balance. Six of the 10 infants were delivered by caesarean section and four by vaginal delivery. All the infants were ventilated for hyaline membrane disease. Data from two infants of 26 and 27 weeks' gestation and birthweight 800 and $824 \mathrm{~g}$ respectively who developed hypernatraemia, and from one infant of 30 weeks' gestation and birthweight $1400 \mathrm{~g}$ who developed water overload secondary to inappropriate arginine vasopressin secretion are presented separately. The remaining 7 infants are grouped together. Their mean gestational age was 30.5 (range 27 to 35 ) weeks and mean birthweight 1506 (range 1165 to 2290) g.

The infants were nursed under an Ohio Overhead heater (Ohio Medical Products, USA) and phototherapy was used when necessary to control the plasma bilirubin concentration. Ten per cent glucose in $0 \cdot 18 \%$ saline was the principal intravenous solution used and the volumes given are shown in Fig. 1. Adjustments to sodium and water intake were prescribed by the physician managing the patient.

\section{Methods. \\ Measurement of sodium and water intake}

At first water and sodium intake were measured by weighing the intravenous bottles and drip tubing at the beginning and end of each day and analysing the solutions. Water intake determined by this method compared with water intake estimated from nurses' records was so similar, however, that weighing was abandoned and the records were used instead. The amount of sodium given in milk was determined from the volume of milk given and the chemical analysis of the milk used.

\section{Measurement of faecal sodium loss}

Attempts were made to collect meconium on Whatman's ashless filter papers for analysis but so little was passed that faecal sodium loss was left out of the calculations.
Urine collection

The method is described in Part I. ${ }^{8}$

\section{Analytical methods}

Urine and milk were analysed for sodium by atomic emission spectrophotometry using an Instrumentation Laboratories Model 343 Flame Photometer (Analytical Instrument Division, USA).

\section{Measurement of body weight}

All measurements of body weight were performed by one of us (LR). The infant was weighed on a Marsden Beam Balance (Marsden Weighing Machine Group, UK) accurate to within $\pm 1.0 \mathrm{~g}$. As a preliminary, a record of all attachments was made and their total weight determined by weighing duplicates. Then all monitoring devices were unplugged and drips disconnected and plugged with sterile plugs (No R94 Avon Medicals, UK). The scales were set to the previous day's weight and then the weight of the baby and attachments was quickly determined. The weight of the baby was calculated as the difference.

\section{Estimates of extrarenal water loss}

Extrarenal water losses were defined for the purpose of this paper as:

Water intake (g/day)-(urinary water (g/day) +change in body weight (g/day)).

This estimate ignores any change in body dry weight, which we were unable to measure. Since total body water in these infants is approximately $80 \%$ of body weight, however, ${ }^{2}$ calculations showed that the error would not alter materially the practical value of the estimates of extrarenal water loss.

\section{Results}

The changes in plasma sodium concentrations, sodium balance, and fluid intake and output in the group of 7 infants are shown in Fig. 1. The mean plasma sodium concentration soon after birth was $133 \mathrm{mmol} / \mathrm{l}$ indicating that water overload was present at delivery in some infants. There was no significant change in the plasma sodium concentration over the first 24 hours but during the second day this rose towards normal values.

Mean sodium balance was positive at age 1 and 2 days but became negative at age 3,4 , and 5 days. Because it was not possible to weigh all the infants regularly estimates of insensible water loss and therefore water balance could not be made for the whole group. Urine volume on day one was, however, lower than at any other time and averaged 41 (range 17 to 69 ) $\mathrm{ml} / \mathrm{kg} / \mathrm{day}$, while fluid intake averaged $89 \mathrm{ml} / \mathrm{kg} /$ day. Since the mean plasma 

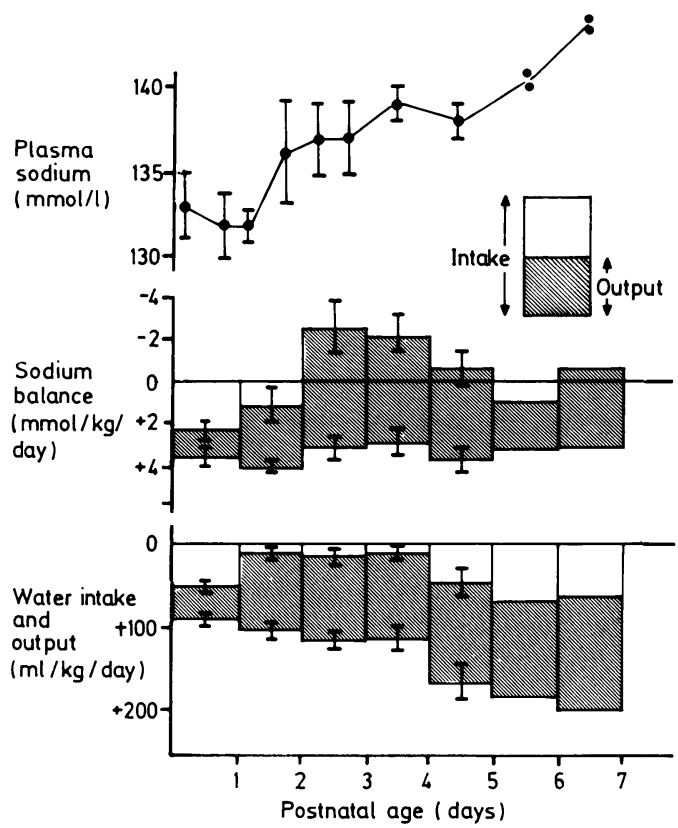

Fig. 1 Changes (mean SEM) in plasma sodium concentration, sodium balance, and water intake and output in 7 preterm infants of mean gestation 30.5 weeks and mean birthweight $1506 \mathrm{~g}$.

sodium concentration did not rise over the first 24 hours and sodium balance was positive, it can be deduced that mean water balance was also positive. During the second, third, and fourth days as the plasma sodium rose the urine volume increased and was so close to intake that together with insensible water loss (see the Table) output must have exceeded intake leading to negative water balance.

Fig. 2 gives examples of serial measurements in one of the 7 infants who was weighed on four occasions enabling estimates of insensible water loss to be made. Both sodium and water balance were positive during the first 24 hours of life and since the

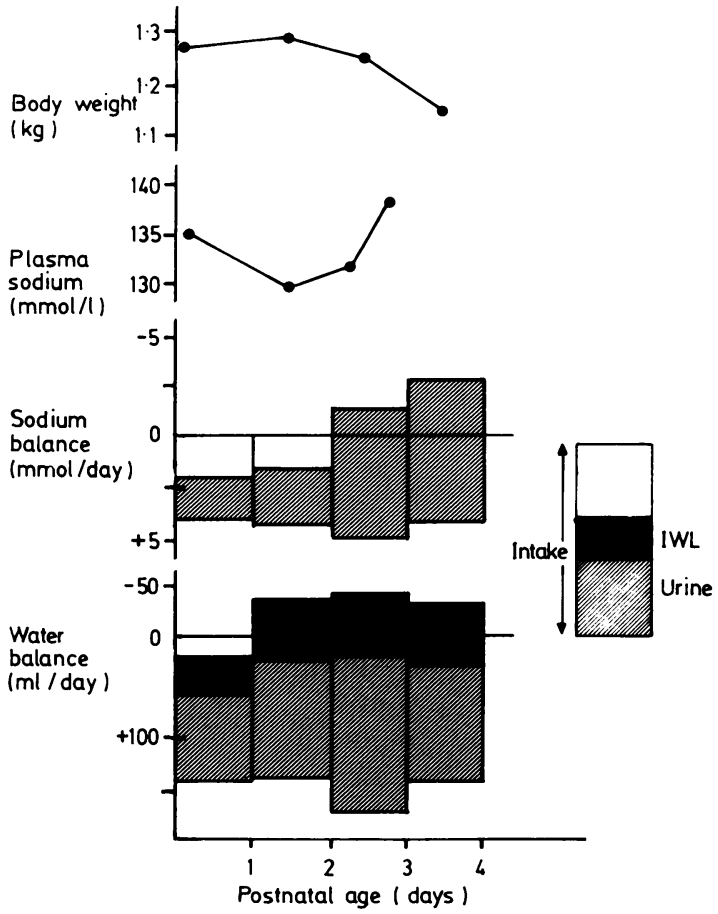

Fig. 2. Changes in body weight, plasma sodium concentration, sodium balance, and water balance in a single infant of birthweight $1270 \mathrm{~g}$ and gestational age 30 weeks after birth. The black areas represent estimates of insensible water loss (IWL).

plasma sodium concentration fell as the body weight increased, water must have been retained in excess of sodium. A spontaneous increase in water excretion occurred on day two and in sodium excretion on day three, leading to negative sodium and water balance. Since the plasma sodium concentration rose as the weight fell water must have been lost in excess of sodium.

Because changes in sodium balance were in opposition to the changes in plasma sodium concen-

Table Estimates of insensible water loss ( $\mathrm{ml} / \mathrm{kg} / \mathrm{hour}$ )

\begin{tabular}{|c|c|c|c|c|c|c|c|c|c|}
\hline \multirow[t]{2}{*}{ Baby } & \multirow{2}{*}{$\frac{\text { Gestational age }}{(w k s)}$} & \multirow{2}{*}{$\underset{(g)}{\text { Birthucight }}$} & \multicolumn{4}{|c|}{ Postmatal age (days) } & \multirow[b]{2}{*}{5} & \multirow[b]{2}{*}{6} & \multirow[b]{2}{*}{7} \\
\hline & & & $l$ & 2 & 3 & $t$ & & & \\
\hline 1 & 30 & 1620 & 1.5 & $1 \cdot 4$ & 1.5 & $2 \cdot 1)$ & 1.5 & $2 \cdot 4$ & $2 \cdot 3$ \\
\hline 2 & 30 & 1270 & 1.4 & $2 \cdot 0$ & $2 \cdot 2$ & $2 \cdot 2$ & & & \\
\hline 3 & 27 & 116.5 & $2 \cdot 4$ & 2.9 & 1.6 & 1.7 & & & \\
\hline 4 & 26 & $8(0)$ & 3.6 & 6.2 & $2.011^{\circ}$ & 1.6 & $1.5^{\circ}$ & $1.5^{\circ}$ & \\
\hline 5 & 27 & 824 & 4.8 & $4 \cdot 8$ & $4.11^{\circ}$ & $3 \cdot 2$ & 3.2 & 3.1 & \\
\hline
\end{tabular}

'Phototherapy.

+Humidification. 
tration, it is clear that changes in water balance rather than sodium balance were the principal determinant of the plasma sodium concentration in these 7 infants.

Infants with hypernatraemia. The two infants with hypernatraemia were the smallest and most immature studied. Changes in sodium balance and water balance were similar in both and the data from only one are therefore shown in Fig. 3. Sodium balance during the first 48 hours of life was positive but not sufficiently so to have affected materially the plasma sodium concentration. The principal cause of the hypernatraemia was negative water balance due to very high insensible water losses averaging 4.9 $\mathrm{ml} / \mathrm{kg} /$ hour during the first two days of life (see the Table). As the hypernatraemia developed the plasma osmolality, urine osmolality, and urinary arginine vasopressin excretion increased ${ }^{\mathrm{X}}$ indicating an appropriate antidiuretic response to the period of

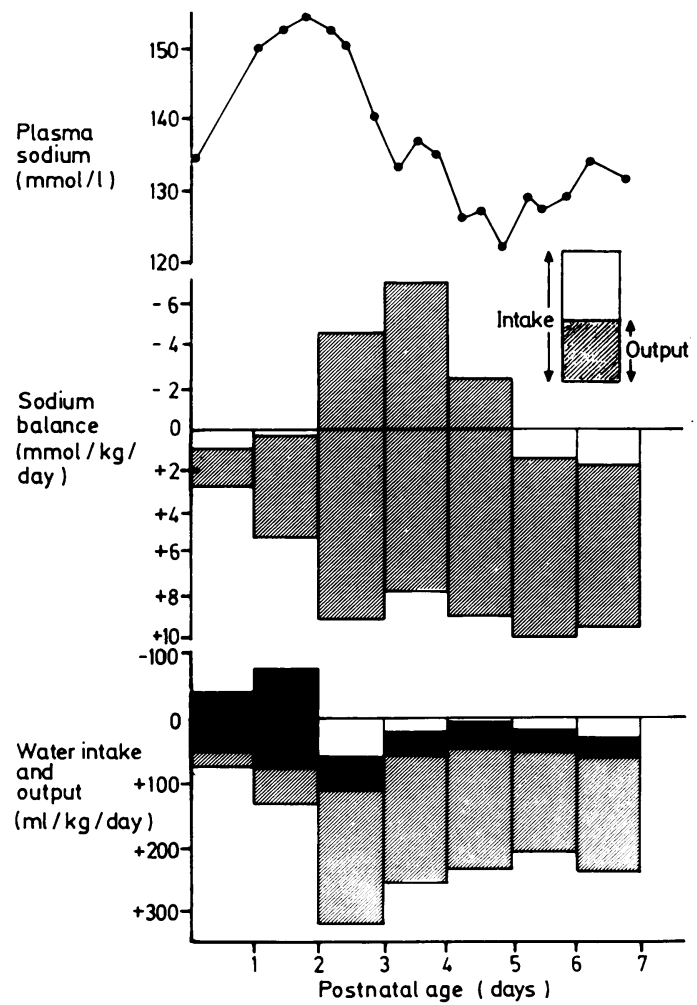

Fig. 3. Changes in plasma sodium concentration, sodium balance, and water balance in an infant of birthweight $800 \mathrm{~g}$ and gestational age 26 weeks who developed hypernatraemia due to high insensible water losses. The black areas represent estimates of insensible water loss. dehydration. The hypernatraemia was corrected by increasing water intake and decreasing evaporative water losses by increasing the relative humidity of the air surrounding the baby. Water balance became positive and sodium balance negative leading to a fall in the plasma sodium concentration.

Extrarenal water loss. Estimates of extrarenal water losses in those infants who were weighed are given in the Table. These averaged 2.6 (range 1.4 to 6.2 ) $\mathrm{ml} / \mathrm{kg} /$ hour.

Obligatory sodium loss after birth. Cumulative, mean, net negative sodium balance in the 7 infants represented in Fig. 1 and in the two infants with hypernatraemia was $-5.1 \mathrm{mmol}$ sodium $/ \mathrm{kg}$, equivalent to a mean loss of extracellular fluid amounting to $4 \cdot 2 \%$ of body weight. For reasons outlined in the discussion this is probably an under estimate.

Effect of inappropriate secretion of arginine vasopressin on sodium and water balance. Eight of the 10 infants had raised urinary arginine vasopressin excretion associated with a rise in urine osmolality that occurred at a time when their plasma sodium was $<135 \mathrm{mmol} / \mathrm{l}$.

Fig. 4 gives details of urinary arginine vasopressin excretion and of changes in the plasma sodium concentration, sodium balance, and water intake and output in one of the infants who developed water intoxication. His plasma sodium concentration was normal at birth but fell over the first 30 hours to $123 \mathrm{mmol} / \mathrm{l}$. This fall was associated with a raised urinary arginine vasopressin excretion after birth and a sharp increase in excretion of this hormone between 24 and 32 hours of age-the cause of which is not clear, though it followed a grade I periventricular haemorrhage. ${ }^{8}$ Because the results of the arginine vasopressin analysis were not available at the time the cause of the hyponatraemia was not appreciated, in spite of the fact that the baby was passing small volumes of concentrated urine. ${ }^{8}$ Instead of water restriction, sodium supplements of $11 \mathrm{mmol} / \mathrm{kg} /$ day were given to this infant without increasing water intake proportionately. His plasma sodium concentration rose and water balance was almost certainly positive at this time. Between 36 and 64 hours of age there was a massive release of arginine vasopressin associated with the development of a right grade IV intraventricular haemorrhage and his plasma sodium concentration began to decline again. Though sodium balance became negative, net water balance was probably positive until after the last big peak of urinary arginine vasopressin excretion on day five. On day 6 when his 

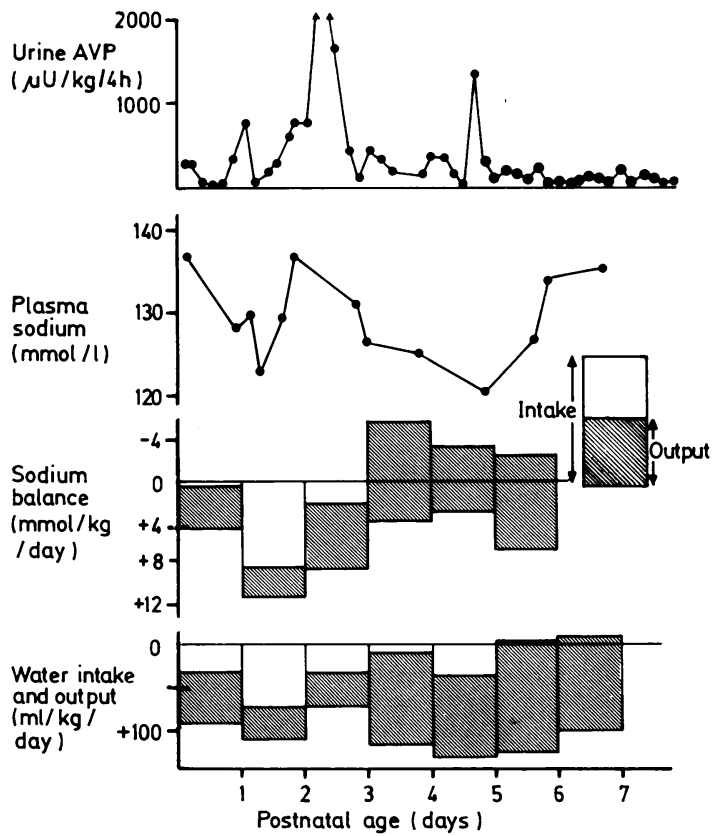

Fig. 4. Changes in urinary arginine vasopressin (AVP) excretion, plasma sodium balance, and water intake and output in an infant of birthweight $1400 \mathrm{~g}$ and gestational age 30 weeks who developed inappropriate secretion of $A V P$ and water overload secondary to hyaline membrane disease and intracranial haemorrhage.

urinary arginine vasopressin excretion fell, urine volume exceeded water intake for the first time, water balance became negative, and the infant's plasma sodium concentration rose to normal.

\section{Discussion}

It is well known that errors in metabolic balance techniques are additive and tend always to overestimate positive and underestimate negative balances." Moreover, since this study was conducted among very sick infants metabolic balance measurements were difficult and some errors were inevitable. For these reasons the obligatory sodium loss is almost certainly an underestimate and it would be quite wrong to make quantitative estimates of changes in body composition from these results. Nevertheless the direction of the changes were very consistent and valuable deductions can be made.

Sodium balance. The changes in sodium balance were very similar in all the infants, and sodium balance was invariably positive at age 1 day on a mean intake of $3.6 \mathrm{mmol} / \mathrm{kg} /$ day. Balance thereafter became negative returning to positive by the fifth to sixth day (Fig. 1).

Our data suggest that a negative sodium balance is not affected by increasing sodium intake since the infant in Fig. 3 received twice as much sodium as the infants in Fig. 1, with no change in the pattern of postnatal sodium loss. In particular, the sodium diuresis illustrated in Fig. 3 began when the baby was dehydrated showing that this was not caused by volume expansion in this infant. ${ }^{10}$ The negative sodium balance after birth seems to be an obligatory, self limiting event associated with contraction of extracellular fluid volume. Our findings therefore confirm the similar conclusions of Butterfield et al. ${ }^{1}$ It is clear from the data in Figs. 1 and 2 that the changes in plasma sodium concentrations reflect mainly changes in water balance rather than sodium balance. These results therefore contradict those of Engelke $e t \mathrm{al}^{3}$ who concluded that the negative sodium balance was the main cause of the hyponatraemia in their patients. Our results show that in the first week of life when the sodium intake is in the region of 3 to $4 \mathrm{mmol} / \mathrm{kg} / \mathrm{day}$, negative sodium balance is not an important cause of hyponatraemia. These conclusions agree with those of Lorenz et $a l^{4}$ who showed that normal plasma sodium concentrations could be maintained with no ill effect on even lower sodium intakes if water balance was carefully controlled by daily weighing.

Water balance. The initial hyponatraemia shown in Fig. 1 was almost certainly the result of maternal water overload as described by Tarnow-Mordi et al. ${ }^{11}$ The positive water balance on the first day, however, was probably due to raised plasma arginine vasopressin concentrations associated with vaginal delivery $^{12}$ and deteriorating hyaline membrane disease $^{x}$ and to the very low glomerular filtration rate on the first day of life. The average of reported values for glomerular filtration rate in infants of 33 weeks' gestation or less during the first day is only $0.3 \mathrm{ml} / \mathrm{kg} /$ minute. ${ }^{13}{ }^{14}$ Since depression of the glomerular filtration rate has been shown to occur in hyaline membrane disease ${ }^{15}$ the actual values in these infants may be even lower.

The negative water balance that occurred on the second to fourth days (Fig. 1) was due to an increase in urine volume. After birth there is a fall in renal vascular resistance leading to increased renal blood flow $^{16}$ and perfusion of cortical nephrons ${ }^{17}$ is which results in an increase in effective glomerular filtration pressure and a rise in the glomerular filtration rate. ${ }^{19}$ Reported values for glomerular filtration rate in infants of 33 weeks' gestation or less, aged 2 to 3 days, average $1.0 \mathrm{ml} / \mathrm{kg} /$ minute $e^{1.314}$ indicating a 
threefold rise since birth. By 7 to 14 days of age the glomerular filtration rate averages $1.6 \mathrm{ml} / \mathrm{kg} /$ minute ${ }^{1420}$ so the rate of increase declines after age 3 days. The big increase after birth suggests that the glomerular filtration rate may be less likely to limit water excretion after the first 24 hours of life.

Causes of hyponatraemia and hypernatraemia. Changes in plasma sodium concentrations observed in these infants resulted in the main from changes in body water and it is noteworthy that the sodium balance was often positive when the plasma sodium concentration was falling and negative when it was rising (Figs. 1, 2, and 4). The only two exceptions were the infants with hypernatraemia (Fig. 3). In particular, inappropriate arginine vasopressin release associated with intracranial haemorrhage, pneumothorax, or acute deterioration of respiratory function during hyaline membrane disease was very common, ${ }^{8}$ and was the most frequent, though often unrecognised, cause of hyponatraemia in the first week of life (Fig. 4). Late hyponatraemia described by Day $e t a l^{11}$ has apparently a different cause. Sodium balance was positive in their patients and the hyponatraemia, which was probably due to limited tubular sodium reabsorption, ${ }^{22-25}$ could be corrected by increasing the intake of sodium to about $3.0 \mathrm{mmol} / \mathrm{kg} /$ day. ${ }^{26}$ Hypernatraemia in this study occurred only in the most immature infants and was caused mainly by their high insensible water loss (Table), while the positive sodium balance on day one made only a small contribution. It is reassuring that our estimates of extrarenal water loss using very different methods are very close to those for insensible water loss in the published reports. ${ }^{5-7}$

These findings have important implications for the management of sick, preterm infants. They shown that sodium intake in the first week of life need not exceed 3 to $4 \mathrm{mmol} / \mathrm{kg} /$ day and that if water balance is controlled as it was in the study of Lorenz et $a l,{ }^{4}$ a sodium intake of as little as 1.0 $\mathrm{mmol} / \mathrm{kg} /$ day may suffice for some. Sodium diuresis and negative balance seem to be a self limiting physiological event which should not be taken on its own as a signal to increase sodium intake. Indeed it may be particularly dangerous to treat hyponatraemia caused by water overload with large amounts of sodium. In the infant illustrated in Fig. 4 it is possible that the intracranial haemorrhage was precipitated by expanding extracellular fluid volume due to prescribing extra sodium, rather than fluid restriction. Normal or excessive postnatal weight loss in the presence of hyponatraemia, however, is certainly an indication for increasing sodium intake.

When an event known to cause inappropriate release of arginine vasopressin is identified it should be possible to prevent water overload developing by fluid restriction and by checking its effectiveness with regular weighing. Great caution must be exercised in the interpretation of urine osmolality (or specific gravity) because, whereas a rise in osmolality may indicate dehydration requiring an increase in water intake, it may equally indicate inappropriate arginine vasopressin secretion necessitating a reduction in water intake. ${ }^{8}$ The urinary sodium concentration can also be very misleading because of the sodium diuresis after birth. We would emphasise therefore that the two most useful measures of sodium and water balance are the plasma sodium concentration and accurate measurement of body weight.

\section{References}

1 Butterfield J, Lubchenko L. Bergstedt J, O'Brien D. Patterns in electrolyte and nitrogen balance in the newborn premature infant. Pediatrics 1960;26:777-91

- Cassady G, Milstead, RR. Antipyrine studies and cellwater estimates in infants of low birth weight. Pediatr Res 1971:5: 673-82.

Engelke SC, Shah BL. Vasan U, Raye JR. Sodium balance in very low birth weight infants. $J$ Pediatr 1978:93:837-41.

4 Lorenz JM, Kleinman LI, Kotagal U, Reller MD. Water balance in very low birth weight infants: relationship to water and sodium intake and effect on outcome. $J$ Pediatr 1982;101:423-32.

Hammarlund K. Sedin G. Stromberg B. Transepidermal water loss in newborn infants VII: relationship to postnatal age in very preterm and appropriate for gestational age infants. Acta Paediatr Scand 1982:71:369-74.

${ }^{\circ}$ Okken A, Jonxis JHP. Rispens P, Zijlstra WG. Insensible water loss and metabolic rate in low birthweight newborn infants. Pediatr Res 1979;13:1072-5.

7 Wu PK. Hodgman JE. Insensible water loss in preterm infants: changes with postnatal development and non ionising radiant energy. Pediatrics 1974:54:7()4-12.

${ }^{\rtimes}$ Rees L, Brook CGD, Shaw JCL, Forsling ML. Hyponatraemia in the first week of life in preterm infants. Part I. Studies of arginine vasopressin secretion and the renal response to the hormone. Arch Dis Child 1984;59:414-22.

"Wallace WM, Weill WB. Taylor A. The effect of variable protein and mineral intake upon body composition. Ciba Colloquia on Ageing 1958:4:116-38.

10 Leake RD, Zakauddin S, Trygstad CW, Fu P. Oh W. The effects of large volume intravenous fluid infusion on neonatal renal function. J Pediatr 1976:89:968-72.

$"$ Tarnow-Mordi WO, Shaw JCL, Liu D. Gardner D. Flynn FV. Iatrogenic hyponatraemia of the newborn due to maternal fluid overload: a prospective study. Br Med J 1981:283:639-42.

12 Rees L. Forsling ML, Brook CGD. Vasopressin levels in the newborn. Clin Endocrinol 198();12:357-63.

13 Arant BS, Jr. Developmental patterns of renal functional maturation compared in the neonate. J Pediatr 1978:92:705-12.

14 Fawer C-L. Torrado A, Guignard J-P. Maturation of renal function in full term and premature neonates. Helv Paediatr Acta 1979:34:11-21.

15 Guignard J-P. Torrado A, Mazouri SM, Gautier E. Renal function in respiratory distress syndrome. I Pediatr 1976;88: 845-50.

16 Gruskin AB, Edelmann CM, Jr, Yuan S. Maturational changes in renal blood flow in piglets. Pediatr Res 1970:4:7-13. 
${ }^{17}$ Aschinberg LC. Goldsmith DI. Olbing H, Spitzer A, Edelmann CM. Jr. Blaufox MD. Neonatal changes in renal blood flow distribution in puppies. Am J Phvsiol 1975:228:1453-61.

is Olbing H, Blaufox MD. Aschinberg LC, Bernstein J. Spitzer A. Edelmann CM. Postnatal changes in renal glomerular blood flow distribution in puppies. J Clin Invest 1973;52:2885-95.

19) Spitzer A. Edelmann CM. Jr. Maturational changes in pressure gradients for glomerular filtratioin. Am $J$ Physiol 1971:221:1431-5.

20 Leake RD. Trygstad C. Oh W. Inulin clearance in the newborn infant. Relationship to gestational and postnatal age. Pediatr Res 1976;10:759-62.

2 Day GM. Radde IC. Balfe JW. Chance GW. Electrolyte abnormalities in very low birthweight infants. Pediatr Res 1976:10:522-6.

22 Ross B. Cowett RM. Oh W. Renal functions of low birth weight infants during the first two months of life. Pediatr Res 1977:11:1162-4.
23 Sulyok E, Varga F, Györy E, Jobst K. Csaba IF. Postnatal development of renal sodium handling in premature infants. J Pediatr 1979:95:787-92.

${ }^{24}$ Aperia A. Broberger D. Elinder G. Herin P. Zetterström R. Postnatal development of renal function in preterm and full term infants. Acta Paediatr Scand 1981:70:183-7.

25 Al-Dahhan J. Haycock GB. Chantler C. Stimmler L. Sodium homeostasis in mature and immature neonates. 1. Renal aspects. Arch Dis Child 1983;58:335-42.

26 Roy RN. Chance GW. Radde IC. Hill DE. Willis DM. Sheepers $\mathrm{J}$. Late hyponatraemia in very low birthweight infants $(<1 \cdot 3 \mathrm{~kg})$. Pediatr Res 1976:10:526-31.

Correspondence to Dr J C L Shaw. Department of Paediatrics. The Rayne Institute. University Street, London WCIE 6JJ.

Received 1 February 1983 